\title{
MIXED CONVECTION BOUNDARY LAYER FLOW ON A VERTICAL SURFACE IN A POROUS MEDIUM SATURATED BY A NANOFLUID WITH SUCTION OR INJECTION
}

\author{
${ }^{1}$ Yasin, M.H.M., ${ }^{1}$ N.M. Arifin, ${ }^{2}$ R. Nazar, ${ }^{1}$ F. Ismail and ${ }^{3}$ I. Pop \\ ${ }^{1}$ Institute for Mathematical Research and Department of Mathematics, \\ Universiti Putra Malaysia, 43400 UPM Serdang, Selangor, Malaysia \\ ${ }^{2}$ School of Mathematical Sciences, Faculty of Science and Technology, \\ Universiti Kebangsaan Malaysia, 43600 UKM Bangi, Selangor, Malaysia \\ ${ }^{3}$ Department of Mathematics, Babeş-Bolyai University, 400082 Cluj-Napoca, CP 253, Romania
}

Received 2013-02-07, Revised 2013-03-13; Accepted 2013-05-10

\begin{abstract}
An analysis of the steady mixed convection boundary layer flow past a vertical permeable surface embedded in a porous medium saturated by a nanofluid is performed in this study. Numerical solutions of the similarity equations are obtained using the shooting method. Three types of metallic or nonmetallic nanoparticles, namely Copper $(\mathrm{Cu})$, Alumina $\left(\mathrm{Al}_{2} \mathrm{O}_{3}\right)$ and Titania $\left(\mathrm{TiO}_{2}\right)$ are considered by using a water-based fluid to investigate the effect of the solid volume fraction or nanoparticle volume fraction parameter $\varphi$ of the nanofluid. The numerical results of the skin friction coefficient and the velocity profiles are presented and discussed. It is found that the imposition of suction is to increase the velocity profiles and to delay the separation of boundary layer, while the injection parameter decreases the velocity profiles. On the other hand, the range of solutions for the injection case is largest for $\mathrm{Al}_{2} \mathrm{O}_{3}$ nanoparticles and smallest for $\mathrm{Cu}$ nanoparticles.
\end{abstract}

Keywords: Boundary Layer, Nanofluid, Mixed Convection, Permeable Surface, Porous Medium

\section{INTRODUCTION}

The problem of convection in a porous medium provides one of the basic scenarios for heat transfer theory and thus is of considerable theoretical and practical interest and has been extensively studied. Excellent reviews of the topic can be found in the books by Nield and Bejan (2006); Pop and Ingham (2001); Ingham and Pop (2005) and Vadasz (2008). The most basic problem for natural or free convection in a porous medium past a vertical flat plat was first studied by Cheng and Minkowycz (1997). There are several numerical studies on the mixed convection in a porous media and we mention here those by Harris et al. (2009); Rosali et al. (2011); Imran et al. (2012) and Mukhopadhyay (2012). On the other hand, nanofluids are engineered by suspending nanoparticles with average size below $100 \mathrm{~nm}$ in traditional heat transfer fluids such as water, oil and ethylene glycol. Fluids such as water, oil and ethylene glycol are poor heat transfer fluids, since the thermal conductivity of these fluids play important role on the heat transfer coefficient between the heat transfer medium and the heat transfer surface. Choi and Guarino (1995) showed that the addition of small amount (less than $1 \%$ by volume) of nanoparticles to conventional heat transfer liquids increased the thermal conductivity of the fluids up to approximately two times. Therefore, the effective thermal conductivity of nanofluids is expected to enhance heat transfer compared to the conventional heat transfer liquids.

Some numerical and experimental studies on the forced and natural convection using nanofluids related with differentially heated enclosures have been considered by Jou and Tzeng (2006); Tiwari and Das (2007); Abu-Nada (2008); Oztop and Abu-Nada (2008);

Corresponding Author: N.M. Arifin, Institute for Mathematical Research and Department of Mathematics, Universiti Putra Malaysia, 43400 UPM Serdang, Selangor, Malaysia 
Muthtamilselvan et al. (2010) and Ghasemi and Aminossadati (2010). Nield and Kuznetsov (2009) have studied the Cheng and Minkowycz's problem for natural convective boundary layer flow in a porous medium saturated by a nanofluid taking into account the combined effects of heat and mass transfer in the presence of Brownian motion and thermophoresis as proposed by Buongiorno (2006). Later, Kuznetsov and Nield (2010) examined the natural convective heat transfer in the boundary layer flow of a nanofluid past a vertical flat plate embedded in a porous medium. The steady boundary layer flow of a nanofluid past a stretching sheet using Buongiorno (2006) nanofluid model has been discussed by Khan and Pop (2010). The model they used for the nanofluid incorporates the effects of Brownian motion and thermophoresis and found solution which depends on the Prandtl number Pr, Lewis number Le, Brownian motion number $\mathrm{Nb}$ and thermophoresis number Nt. Also, Bachok et al. (2010) used the Buongiorno (2006) nanofluid equation model for the steady boundary layer flow of a nanofluid past a moving semi-infinite flat plate in a uniform free stream. They assumed that the plate is moving in the same or opposite directions to the free stream to define resulting system of nonlinear ordinary differential equations.

Recently, Ahmad and Pop (2010) considered the steady mixed convection boundary layer flow over a vertical flat plate embedded in a porous medium filled with a nanofluid using the nanofluid equation model proposed by Tiwari and Das (2007). The review papers by Arifin et al. (2011; 2012a); Yasin et al. (2012) and Arifin et al. (2012b) present excellent collections of published papers on nanofluids using model proposed by Tiwari and Das (2007). Therefore, the present investigation deals with the steady mixed convection boundary layer flow past a permeable vertical flat plate embedded in a porous medium saturated with a nanofluid. This study extends the papers by Ahmad and Pop (2010) to the case of permeable surface. Results are presented in tables and figures showing the effects of the constant suction or injection parameters.

\section{MATERIALS AND METHODS}

\subsection{Problem Formulation}

Consider the steady mixed convection boundary layer flow past a vertical semi-infinite plate embedded in a porous medium filled with a nanofluid. It is assumed that the free stream velocity and the ambient temperature (far flow from the plate) are $\mathrm{U}_{\infty}$ and $\mathrm{T}_{\infty}$, respectively. It is also assumed that the temperature of the plate is $T_{w}$, where $T_{w}>T_{\infty}$ corresponds to a heated plate (assisting flow) and $\mathrm{T}_{\mathrm{w}}<\mathrm{T}_{\infty}$ corresponds to a cooled plate (opposing flow). It is also assumed that the convecting fluid and the porous medium are in local thermodynamic equilibrium, the viscous dissipation is neglected, the physical properties of the fluid except the density are constant and that the Boussinesq approximation holds. Following the nanofluid equation model proposed by Tiwari and Das (2007) along with the Boussinesq and boundary layer approximations, it is easy to show that the steady boundary layer equations of the present problem are (Ahmad and Pop, 2010):

$$
\begin{aligned}
& \frac{\partial u}{\partial x}+\frac{\partial v}{\partial y}=0 \\
& \frac{\mu_{n f}}{\mu_{f}} \frac{\partial u}{\partial y}=\frac{g K\left[\varphi \rho_{s} \beta_{s}+(1-\varphi) \rho_{f} \beta_{f}\right]}{\mu_{f}} \frac{\partial T}{\partial y} \\
& u \frac{\partial T}{\partial x}+v \frac{\partial T}{\partial y}=\alpha_{n f} \frac{\partial^{2} T}{\partial y^{2}}
\end{aligned}
$$

Subject to the boundary conditions:

$$
\begin{aligned}
& \mathrm{v}=\mathrm{v}_{\mathrm{w}}, \quad \mathrm{T}=\mathrm{T}_{\mathrm{w}}(\mathrm{x}) \text { at } \mathrm{y}=0 \\
& \mathrm{u} \rightarrow \infty, \mathrm{T} \rightarrow \mathrm{T}_{\infty} \text { as } \mathrm{y} \rightarrow \infty
\end{aligned}
$$

Integrating Equation 2 with the boundary conditions Equation 4, it becomes:

$\frac{\mu_{\mathrm{nf}}}{\mu_{\mathrm{f}}} \mathrm{u}=\frac{\mu_{\mathrm{nf}}}{\mu_{\mathrm{f}}} \mathrm{U}_{\infty}+\frac{\mathrm{gK}\left[\varphi \rho_{\mathrm{s}} \beta_{\mathrm{s}}+(1-\varphi) \rho_{\mathrm{f}} \beta_{\mathrm{f}}\right]}{\mu_{\mathrm{f}}}\left(\mathrm{T}-\mathrm{T}_{\infty}\right)$

Here, $\mathrm{x}$ and $\mathrm{y}$ are the Cartesian coordinates measured along the plate and normal to it, respectively, $u$ and $v$ are the velocity components along $\mathrm{x}$ and $\mathrm{y}$ axes, respectively, $\mathrm{T}$ is the temperature of the nanofluids, $\mathrm{g}$ is the acceleration due to gravity, $\mathrm{v}_{\mathrm{w}}(\mathrm{x})$ is the mass transfer velocity with $\mathrm{v}_{\mathrm{w}}(\mathrm{x})<0$ for suction and $\mathrm{v}_{\mathrm{w}}(\mathrm{x})>0$ for injection, $\varphi$ is the nanoparticle volume fraction, $\mu_{\mathrm{f}}$ is the dynamic viscosity of the base fluid, $\beta_{\mathrm{f}}$ and $\beta_{\mathrm{s}}$ are the coefficients of thermal expansion of the fluid and of the solid, respectively, $p_{f}$ and $p_{s}$ are the densities of the fluid and of the solid fractions, respectively, $\mu_{\mathrm{nf}}$ is the viscosity of the nanofluid and $a_{n f}$ is the thermal diffusivity of the nanofluid, which are given by Oztop and Abu-Nada (2008): 


$$
\begin{aligned}
& \mu_{n f}=\frac{\mu_{f}}{(1-\varphi)^{2.5}}, \quad \alpha_{n f}=\frac{k_{n f}}{\left(\rho C_{p}\right)_{n f}}, \\
& \left(\rho C_{p}\right)_{n f}=(1-\varphi)\left(\rho C_{p}\right)_{f}+\phi\left(\rho C_{p}\right)_{s}, \\
& \frac{k_{n f}}{k_{f}}=\frac{\left(k_{s}+2 k_{f}\right)-2 \varphi\left(k_{f}-k_{s}\right)}{\left(k_{s}+2 k_{f}\right)+\varphi\left(k_{f}-k_{s}\right)}
\end{aligned}
$$

where, $\left(\mathrm{pC}_{\mathrm{p}}\right)_{\mathrm{nf}}$ is the heat capacity of the nanofluid as expressed by Khanafer et al. (2003) and Abu-Nada (2008) The viscosity of the nanofluid $\mu_{\mathrm{nf}}$ can be approximated as the viscosity of a base fluid $\mu_{\mathrm{f}}$ containing dilute suspension of fine spherical particles. The effective thermal conductivity of the nanofluid $\mathrm{k}_{\mathrm{nf}}$ is approximated by the Maxwell-Garnett's model, which is found to be appropriate for studying the heat transfer enhancement using nanofluids (Abu-Nada, 2008) We now look for similarity solutions of Equation 3 and 5 subject to the boundary conditions (4) of the following form:

$$
\begin{aligned}
& \psi=\alpha_{f}\left(2 \mathrm{Pe}_{\mathrm{x}}\right)^{1 / 2} \mathrm{f}(\eta), \theta(\eta)=\frac{\left(\mathrm{T}-\mathrm{T}_{\infty}\right)}{\left(\mathrm{T}_{\mathrm{w}}-\mathrm{T}_{\infty}\right)}, \\
& \eta=\frac{\left(\mathrm{Pe}_{\mathrm{x}}\right)^{1 / 2} \mathrm{y}}{\mathrm{x} \sqrt{2}}
\end{aligned}
$$

where, $P e_{x}=U_{\infty} X / a_{f}$ is the local Peclet number for the porous medium and $\psi$ is the stream function, which is defined in the usual way as $u=\partial \psi / \partial y$ and $v=\partial \psi / \partial x$. Thus, we have Equation (8):

$$
\begin{aligned}
& u=U_{\infty} f^{\prime}(\eta), \\
& v=-\frac{1}{2} \frac{\alpha_{f}\left(2 P e_{x}\right)^{1 / 2}}{x}\left[f(\eta)-\eta f^{\prime}(\eta)\right]
\end{aligned}
$$

where, primes denote differentiation with respect to $\eta$. In order that Equation 1 to 3 subject to the boundary conditions 4 admit a similarity solution, we have to consider that $\mathrm{V}_{\mathrm{w}}(\mathrm{X})$ has the following expression Equation (9):

$$
\mathrm{v}_{\mathrm{w}}(\mathrm{x})=-\frac{1}{2} \frac{\alpha_{\mathrm{f}}\left(2 \mathrm{Pe}_{\mathrm{x}}\right)^{1 / 2}}{\mathrm{x}} \mathrm{f}_{0}
$$

where, $f_{0}$ is the constant mass transfer parameter with $\mathrm{f}_{0}>0$ for suction and $\mathrm{f}_{0}<0$ for injection.

Substituting Equation 6 and 7 into Equation 3 and 5 , we obtain the following system of ordinary differential equations:

$$
\frac{1}{(1-\varphi)^{2.5}} f^{\prime}=\frac{1}{(1-\varphi)^{2.5}}+\left[(1-\varphi)+\varphi\left(\frac{\rho_{\mathrm{s}}}{\rho_{\mathrm{f}}}\right)\left(\frac{\beta_{\mathrm{s}}}{\beta_{\mathrm{f}}}\right)\right] \lambda \theta
$$

$$
\frac{\frac{\mathrm{k}_{\mathrm{nf}}}{\mathrm{k}_{\mathrm{f}}}}{(1-\varphi)+\varphi \frac{\left(\rho \mathrm{C}_{\mathrm{p}}\right)_{\mathrm{s}}}{\left(\rho \mathrm{C}_{\mathrm{p}}\right)_{\mathrm{f}}}} \theta^{\prime \prime}+\mathrm{f} \theta^{\prime}=0
$$

Along with the boundary conditions:

$$
f(0)=f_{0}, \quad \theta(0)=1, \quad f^{\prime}(\infty) \rightarrow 1, \quad \theta(\infty) \rightarrow 0
$$

where, $\lambda$ is the constant mixed convection parameter, which is defined as Equation 12:

$\lambda=\frac{\mathrm{Ra}_{\mathrm{x}}}{\mathrm{Pe}_{\mathrm{x}}}$

With $\mathrm{Ra}_{\mathrm{x}}=\mathrm{p}_{\mathrm{f}} \mathrm{gK} \beta_{\mathrm{f}}\left(\mathrm{T}_{\mathrm{w}}-\mathrm{T}_{\infty}\right) \mathrm{x} / \mu_{\mathrm{f}} \mathrm{a}_{\mathrm{f}}$ being the local Rayleigh number for a porous medium. It is worth mentioning that $\lambda>0$ corresponds to an assisting flow (heated plate), $\lambda<0$ corresponds to an opposing flow (cooled plate) and $\lambda=0$ corresponds to the forced convection flow. Further, Equation 10 and 11 can be combined to give single equation:

$\frac{k_{n f} / k_{f}}{(1-\varphi)+\varphi\left(\rho C_{p}\right)_{s} /\left(\rho C_{p}\right)_{f}} f^{\prime \prime}+f f$ " $=0$

Subject to the boundary condition Equation (14):

$$
\begin{aligned}
& f(0)=f_{0}, \\
& \frac{1}{(1-\varphi)^{2.5}} f^{\prime}(0)=\frac{1}{(1-\varphi)^{2.5}} \\
& +\left[(1-\varphi)+\varphi\left(\frac{\rho_{\mathrm{s}}}{\rho_{\mathrm{f}}}\right)\left(\frac{\beta_{\mathrm{s}}}{\beta_{\mathrm{f}}}\right)\right] \lambda, \mathrm{f}^{\prime}(\infty)=1
\end{aligned}
$$

The physical quantity of interest is the skin friction coefficient $\mathrm{C}_{\mathrm{f}}$, which is defined as:

$\mathrm{C}_{\mathrm{f}}=\frac{\tau_{\mathrm{w}}}{\rho_{\mathrm{f}} \mathrm{U}_{\infty}^{2}}$

where $t_{w}$ is the skin friction or the shear stress at the surface of the plate, which is given by:

$$
\tau_{\mathrm{w}}=\mu_{\mathrm{nf}}\left(\frac{\partial \mathrm{u}}{\partial \mathrm{y}}\right)_{\mathrm{y}=0}
$$


Substituting Equation 7 into Equation 15 and 16, we obtain Equation 17:

$$
\left(2 \mathrm{Pe}_{\mathrm{x}}\right)^{1 / 2} \mathrm{C}_{\mathrm{f}}=\frac{1}{(1-\varphi)^{2.5}} \mathrm{f} "(\theta)
$$

\section{RESULTS AND DISCUSSION}

The nonlinear ordinary differential Equation 13 subject to the boundary conditions 14 was solved numerically using the shooting method. This wellknown technique is an iterative algorithm which attempts to identify appropriate initial conditions for a related Initial Value Problem (IVP) that provides the solution to the original Boundary Value Problem (BVP). The shooting method is based on MAPLE "dsolve" command and MAPLE implementation, "shoot" (Meade et al., 1996). The results are given to carry out a parametric study showing the influences of the non-dimensional parameters, namely the mixed convection parameter $\lambda$ and the constant suction/injection parameter $\mathrm{f}_{0}$. Following Oztop and Abu-Nada (2008) we have considered the range of nanoparticles volume fraction $\varphi$ as $0 \leq \varphi \leq 0.2$. The thermophysical properties of fluid and nanoparticles $\left(\mathrm{Cu}, \mathrm{Al}_{2} \mathrm{O}_{3}, \mathrm{TiO}_{2}\right)$ used in this study are given in Table 1. In order to validate the accuracy of the numerical method used, the present results for the skin friction coefficient $\mathrm{f}^{\prime \prime}(0)$ when $\varphi=0.1$ and $\varphi=0.2$ for $\mathrm{Cu}$ nanoparticles and various values of $\lambda$ are compared with those of Ahmad and Pop (2010), as shown in Table 2 and 3, respectively. It is clearly seen that the comparison shows very good agreement. Table $\mathbf{2}$ and $\mathbf{3}$ also illustrate the influence of the suction and injection parameter $\mathrm{f}_{0}=0.5$ (suction), 0 (impermeable) and -0.5 (injection) for $\mathrm{Cu}$ nanoparticles and various values of $\lambda$. It should be noticed that the results given in the parentheses are the second (dual) solutions. The results indicate that the imposition of suction $\left(\mathrm{f}_{0}>0\right)$ at the surface has the tendency to increase the skin friction coefficient $f^{\prime \prime}(0)$ but for the case of surface injection $\left(\mathrm{f}_{0}<0\right)$, the skin friction coefficient $\mathrm{f}^{\prime \prime}(0)$ decreases. Based on our computations, the critical values of $\lambda$ (say $\lambda_{\mathrm{c}}$ ) are presented in Table 4, which show a favorable agreement with the previous investigations for the case of impermeable surface $\left(\mathrm{f}^{\prime \prime}(0)\right)$.
Figure 1 shows the variation of the skin friction coefficient $\left(2 \mathrm{Pe}_{\mathrm{x}}\right)^{112} \mathrm{C}_{\mathrm{f}}$ with $\lambda$ for different types of nanoparticles $\left(\mathrm{Cu}, \mathrm{Al}_{2} \mathrm{O}_{3}, \mathrm{TiO}_{2}\right)$ when $\varphi=0.1$. This figure shows that it is possible to get dual solutions of the similarity Equation 13 subjected to boundary conditions 14 for the opposing flow case $(\lambda<0)$ with upper and lower branch solutions. Dual solutions exist for $\lambda_{c}<\lambda>0$, a unique solution exists for $\lambda=\lambda_{c}<0$ and no solutions exist for $\lambda=\lambda_{\mathrm{c}}<0$, where $\lambda_{\mathrm{c}}$ is the critical value of $\lambda$ for which the solution exists. As in similar physical situations, we postulate that the upper branch solutions are physically stable and occur in practice, whilst the lower branch solutions are not physically realizable. This postulate can be verified by performing a stability analysis but this is beyond the scope of the present paper. On the other hand, it is also shown in Fig. 1 that suction $\left(\mathrm{f}_{0}>0\right)$ delays separation compared to the impermeable surface or injection $\left(\mathrm{f}_{0}<0\right)$ cases. This is true for all the three nanoparticles $\left(\mathrm{Cu}, \mathrm{Al}_{2} \mathrm{O}_{3}, \mathrm{TiO}_{2}\right)$ considered.

The variation of the skin friction coefficient $\left(2 \mathrm{Pe}_{\mathrm{x}}\right)^{1 / 2} \mathrm{C}_{\mathrm{f}}$ with suction/injection parameter $\mathrm{f}_{0}$ when $\varphi=$ 0.1 and $\lambda=-1.6$ are presented in Fig. 2. This figure supports the dual nature of the solutions to the boundaryvalue problem (14) and (15). For this value of $\lambda$, there is a critical value $\mathrm{f}_{0 \mathrm{c}}$ of $\mathrm{f}_{0}$, at which there is a saddle-node bifurcation, with two solutions for $\mathrm{f}_{0}>\mathrm{f}_{0 \mathrm{c}}$ and no solutions for $\mathrm{f}_{0}<\mathrm{f}_{0 \mathrm{c}}<0$. This indicates that injection (having $\mathrm{f}_{0}<0$ ) limits the existence of solutions, whereas no such limit appears for suction $\left(f_{0}>0\right)$, with both branches of solutions continuing to large values of $=$ $\mathrm{f}_{0}>0$ (suction). Based on our computations, the values of $\mathrm{f}_{0 \mathrm{c}}$ are $\mathrm{f}_{0 \mathrm{c}}=-0.515151$ for $\mathrm{Al}_{2} \mathrm{O}_{3}, \mathrm{f}_{0 \mathrm{c}}=-0.49825$ for $\mathrm{TiO}_{2}$ and $\mathrm{f}_{0 \mathrm{c}}=-0.33955$ for $\mathrm{Cu}$. This shows that the range of solutions for the injection $\left(\mathrm{f}_{0}<0\right)$ case is largest for $\mathrm{Al}_{2} \mathrm{O}_{3}$ nanoparticles and smallest for $\mathrm{Cu}$ nanoparticles. Figure 3-5 show the velocity profiles for the first (upper branch) and second (lower branch) solutions when $\varphi=0.1$ for different types of nanoparticles, namely $\mathrm{Cu}, \mathrm{Al}_{2} \mathrm{O}_{3}, \mathrm{TiO}_{2}$ respectively. The dashed line refers to the second (lower branch) solution and these solution profiles prove the existence of dual solutions. These figures also show that the suction parameter increases the velocity profiles and the injection parameter decreases the velocity profiles. Finally, it is worth mentioning that all the velocity profiles presented in Fig. 3-5 satisfy the far field boundary conditions (15) asymptotically and thus, support the validity of the dual solutions obtained. 


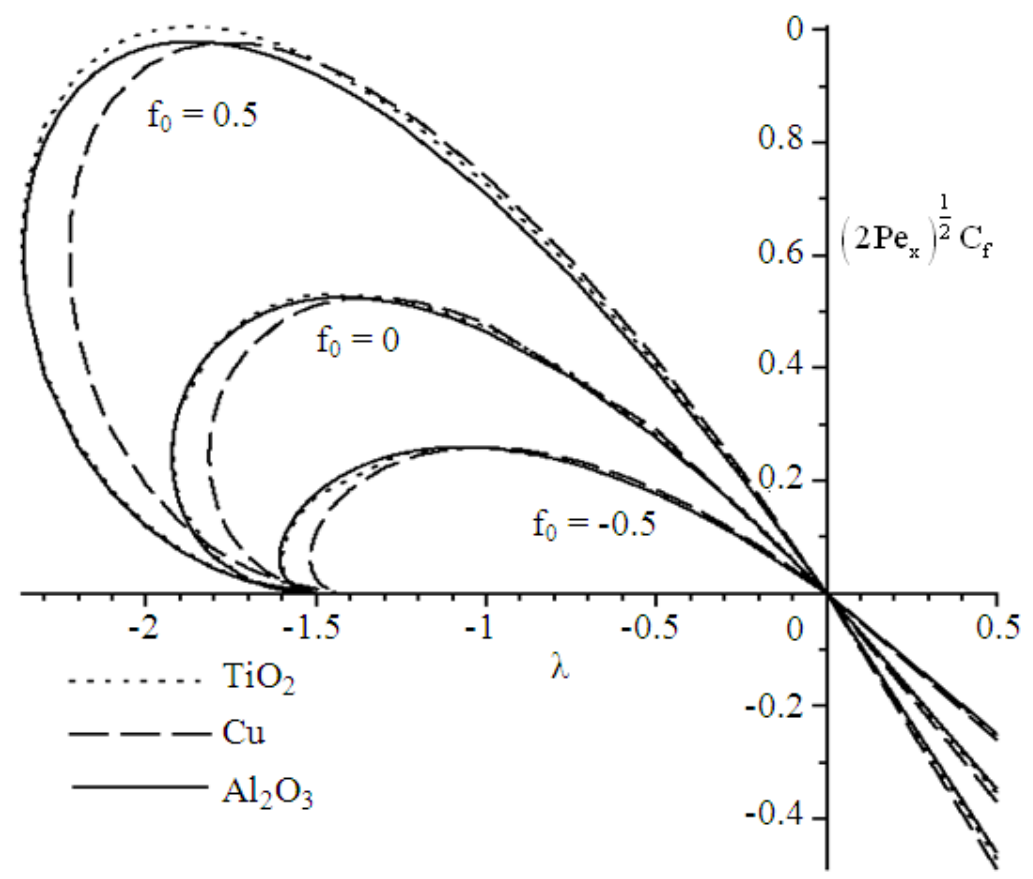

Fig. 1. Variation of the skin friction coefficient $(2 \mathrm{Pe})^{1 / 2} \mathrm{C}_{\mathrm{f}}$ with $\lambda$ for different types of nanoparticles when $\varphi=0.1$ and various values of $\mathrm{f}_{0}$

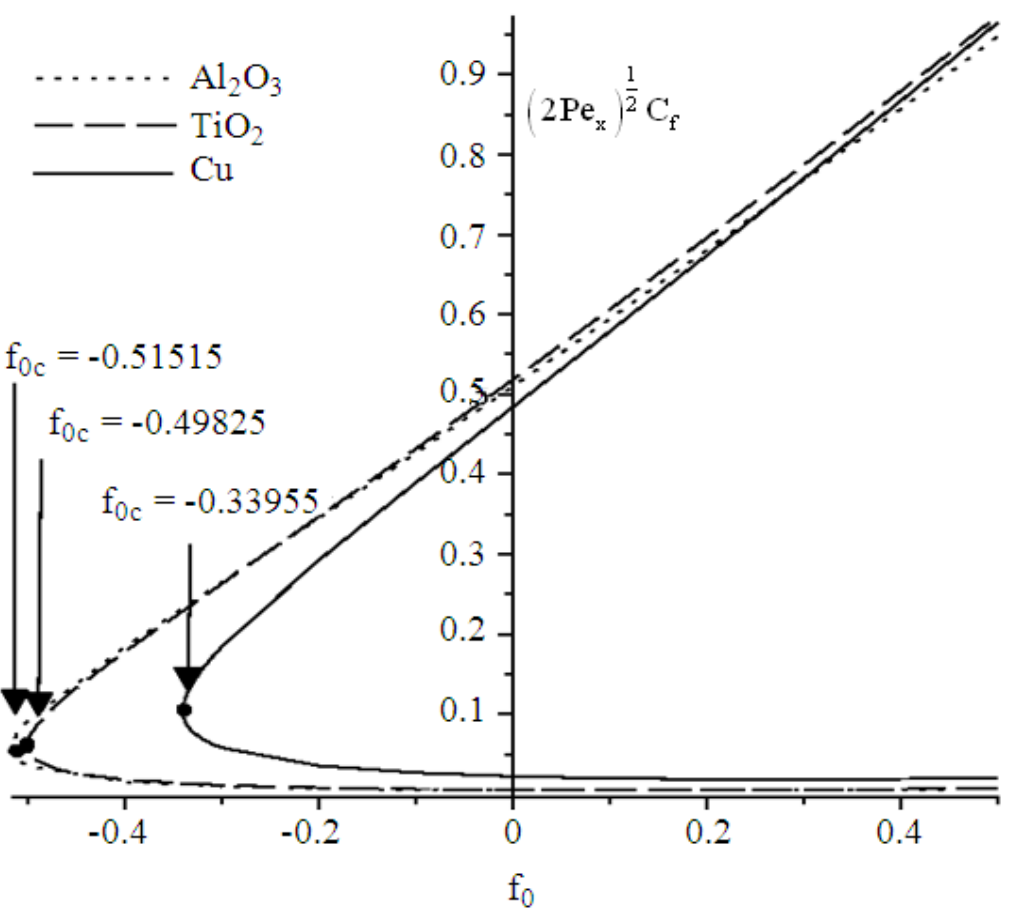

Fig. 2. Variation of the skin friction coefficient $(2 \mathrm{Pe})^{1 / 2} \mathrm{C}_{\mathrm{f}}$ with $\mathrm{f}_{0}$ for different types of nanoparticles when $\varphi=0.1$ and $\lambda=-1.6$ 
Yasin, M.H.M. et al. / Journal of Mathematics and Statistics 9 (2): 119-128, 2013

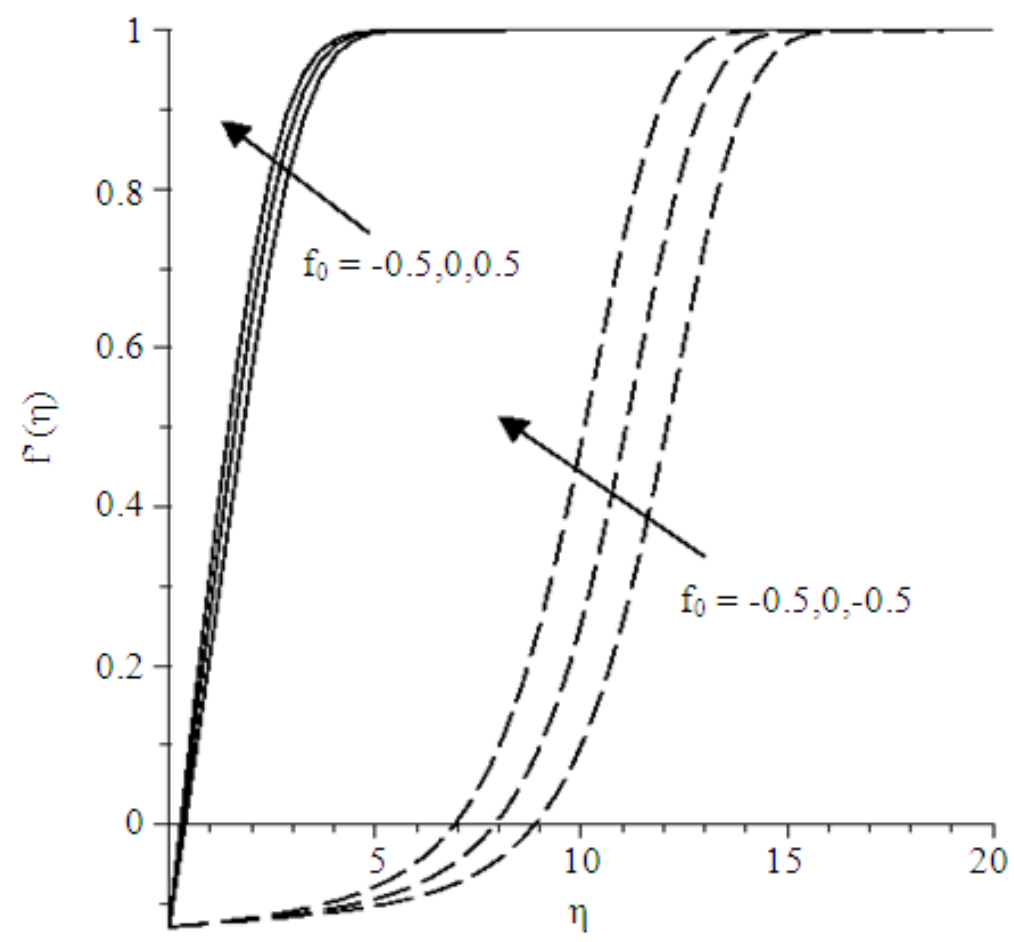

Fig. 3. Velocity profiles $f^{\prime}(\eta)$ for $\mathrm{Cu}$ nanoparticles when $\varphi=0.1, \lambda=-1.6$ and various values of $f_{0}$..

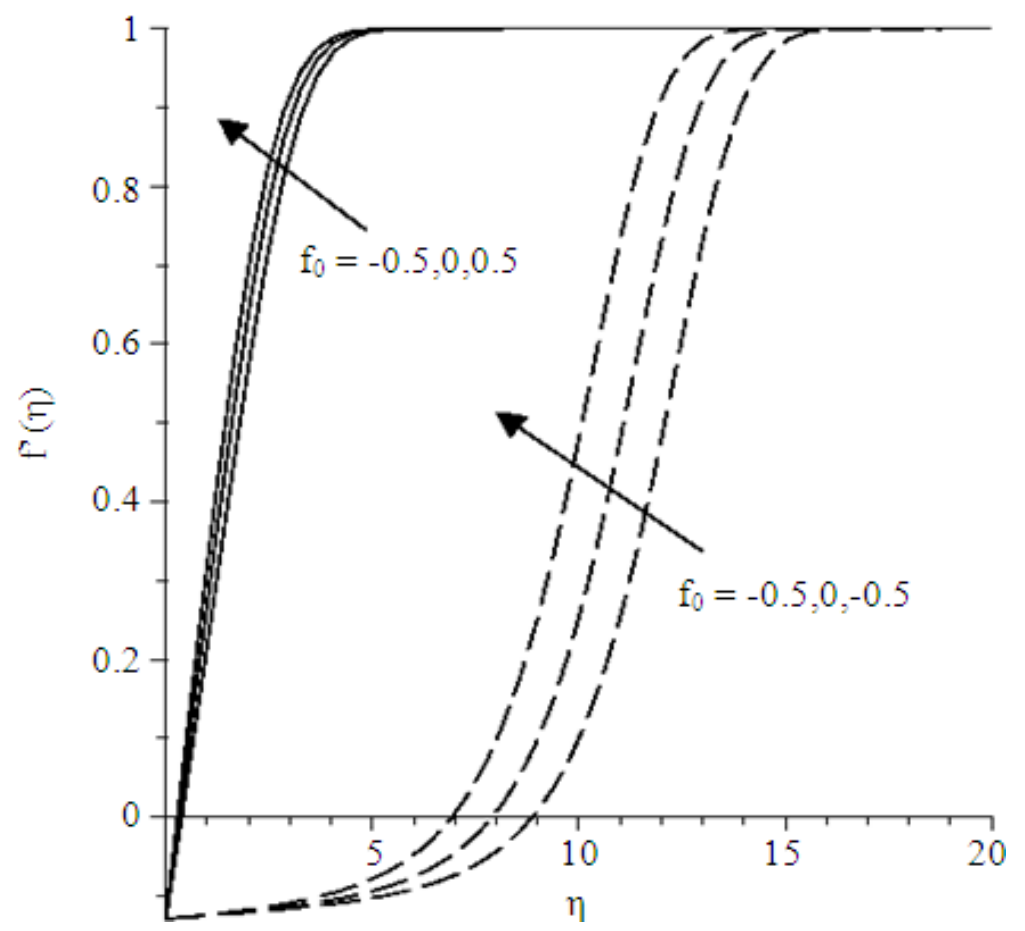

Fig. 4. Velocity profiles $f^{\prime}(\eta)$ for $\mathrm{Al}_{2} \mathrm{O}_{3}$ nanoparticles when $\varphi=0.1, \lambda=-1.6$ and various values of $\mathrm{f}_{0}$ 


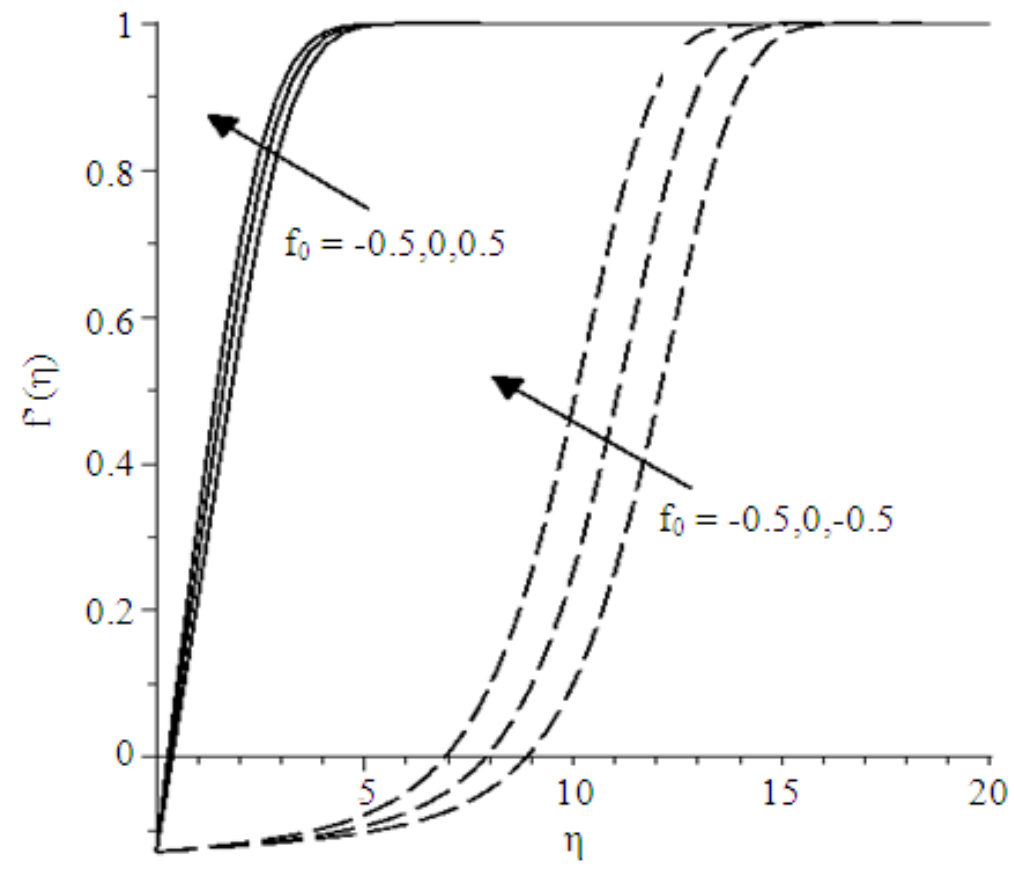

Fig. 5. Velocity profiles $\mathrm{f}^{\prime}(\eta)$ for $\mathrm{TiO}_{2}$ nanoparticles when $\varphi=0.1, \lambda=-1.6$ and various values of $\mathrm{f}_{0}$

Table 1. Thermophysical properties of fluid and nanoparticles (Oztop and Abu-Nada, 2008)

\begin{tabular}{lcrrr}
\hline Physical properties & Fluid phase (water) & $\mathrm{Cu}$ & $\mathrm{Al}_{2} \mathrm{O}_{3}$ & $\mathrm{TiO}_{2}$ \\
\hline $\mathrm{C}_{\mathrm{p}}(\mathrm{J} / \mathrm{kg} \mathrm{K})$ & 4179.000 & 385 & 765 & 686.2000 \\
$\mathrm{P}\left(\mathrm{Kg} / \mathrm{m}^{3}\right)$ & 997.100 & 8933 & 3970 & 4250.0000 \\
$\mathrm{~K}(\mathrm{~W} / \mathrm{mK})$ & 0.613 & 400 & 40 & 8.9538 \\
\hline
\end{tabular}

Table 2. Values of f'(0) for $\mathrm{Cu}$ nanoparticles when $\varphi=0.1$

\begin{tabular}{|c|c|c|c|c|}
\hline \multirow[b]{2}{*}{$\lambda$} & \multirow{2}{*}{$\begin{array}{l}\text { Ahmad and Pop (2010) } \\
f_{0}=0\end{array}$} & \multicolumn{3}{|l|}{ Present } \\
\hline & & $\mathrm{f}_{0}=-0.5$ & $\mathrm{f}_{0}=0$ & $\mathrm{f}_{0}=0.5$ \\
\hline-1.45 & $0.39852(0.00070)$ & $0.11885(0.00345)$ & 0.39852 & 0.71481 \\
\hline-1.50 & $0.39263(0.00333)$ & $0.08218(0.01966)$ & $0.39263(0.00329)$ & 0.72505 \\
\hline-1.51693 & & 0.04746 & & \\
\hline-1.55 & $0.38391(0.00864)$ & & $0.38391(0.00864)$ & $0.73381(0.00633)$ \\
\hline-1.60 & $0.37176(0.01733)$ & & $0.37176(0.01733)$ & $0.74101(0.01572)$ \\
\hline-1.65 & $0.35523(0.03309)$ & & $0.35523(0.03309)$ & $0.74651(0.02394)$ \\
\hline-1.70 & $0.33259(0.04957)$ & & $0.33259(0.04955)$ & $0.75017(0.03387)$ \\
\hline-1.75 & $0.30004(0.07864)$ & & $0.30004(0.07864)$ & $0.75180(0.04587)$ \\
\hline-1.80 & $0.24204(0.13322)$ & & $0.24202(0.13322)$ & $0.75117(0.06014)$ \\
\hline-1.81433 & & & 0.18714 & \\
\hline-1.85 & & & & $0.75117(0.06014)$ \\
\hline-1.90 & & & & $0.74188(0.09678)$ \\
\hline-1.95 & & & & $0.73230(0.12006)$ \\
\hline-2.00 & & & & $0.71850(0.14760)$ \\
\hline-2.10 & & & & $0.67524(0.22106)$ \\
\hline-2.2259 & & & & 0.46446 \\
\hline
\end{tabular}


Table 3. Values of f"'(0) for Cu nanoparticles when $\varphi=0.2$

\begin{tabular}{|c|c|c|c|c|}
\hline \multirow[b]{2}{*}{$\lambda$} & \multirow{2}{*}{$\begin{array}{l}\text { Ahmad and Pop (2010) } \\
f_{0}=0\end{array}$} & \multicolumn{3}{|l|}{ Present } \\
\hline & & $\mathrm{f}_{0}=-0.5$ & $\mathrm{f}_{0}=0$ & $\mathrm{f}_{0}=0.5$ \\
\hline-1.75 & 0.34746 & 0.17741 & 0.34746 & 0.54393 \\
\hline-2.00 & $0.34528(0.00051)$ & $0.13506(0.00159)$ & 0.34528 & 0.57983 \\
\hline-2.14460 & & 0.05192 & & \\
\hline-2.20 & $0.32401(0.01328)$ & & $0.32409(0.01328)$ & 0.59687 \\
\hline-2.25 & $0.31477(0.02044)$ & & $0.31476(0.02044)$ & 0.59919 \\
\hline-2.30 & $0.30313(0.02991)$ & & $0.30311(0.02991)$ & $0.60065(0.02208)$ \\
\hline-2.35 & $0.28848(0.04240)$ & & $0.28845(0.04240)$ & $0.60115(0.02483)$ \\
\hline-2.40 & $0.26954(0.05920)$ & & $0.26949(0.05920)$ & $0.60065(0.03472)$ \\
\hline-2.45 & $0.24337(0.08332)$ & & $0.24321(0.08322)$ & $0.59903(0.04443)$ \\
\hline-2.50 & $0.19693(0.12878)$ & & $0.19559(0.12878)$ & $0.59618(0.05501)$ \\
\hline-2.50987 & & & 0.16214 & \\
\hline-2.60 & & & & $0.58620(0.07921)$ \\
\hline-2.70 & & & & $0.56902(0.11070)$ \\
\hline-2.80 & & & & $0.54140(0.15266)$ \\
\hline-2.9 & & & & $0.49506(0.21336)$ \\
\hline-2.99337 & & & & 0.36095 \\
\hline
\end{tabular}

Table 4. Variation of $\lambda_{\mathrm{c}}$ for different types of nanoparticles $\left(\mathrm{Cu}, \mathrm{Al}_{2} \mathrm{O}_{3}, \mathrm{TiO}_{2}\right)$ for $\varphi=0.1$

\begin{tabular}{lllr} 
& & Phmad and & Present \\
& Pop (2010) & $\lambda_{\mathrm{c}}$ & $\lambda_{\mathrm{c}}$ \\
\hline $\mathrm{Cu}$ & $\mathrm{f}_{0}=-0.5$ & & -1.51690 \\
& $\mathrm{f}_{0}=0$ & -1.814 & -1.81433 \\
& $\mathrm{f}_{0}=0.5$ & & -2.22590 \\
$\mathrm{Al}_{2} \mathrm{O}_{3}$ & $\mathrm{f}_{0}=-0.5$ & & -1.60800 \\
& $\mathrm{f}_{0}=0$ & -1.923 & -1.92351 \\
& $\mathrm{f}_{0}=0.5$ & & -2.36157 \\
$\mathrm{TiO}_{2}$ & $\mathrm{f}_{0}=-0.5$ & -1.918 & -1.59900 \\
& $\mathrm{f}_{0}=0$ & & -1.91902 \\
& $\mathrm{f}_{0}=0.5$ & & -2.36301 \\
\hline
\end{tabular}

\section{CONCLUSION}

The present work deals with the steady mixed convection boundary layer flow past a vertical surface embedded in a porous medium saturated by a nanofluid as considered by Ahmad and Pop (2010). We have extended the previous work by taking into consideration the effects of suction or injection with permeable surface. Further, the governing equations are transformed into ordinary differential equations and are then solved numerically using the shooting method. The effects of the suction or injection parameter, the mixed convection parameter and the nanoparticle volume fraction parameter on the flow and heat transfer characteristics are studied. In general, imposition of suction is to increase the velocity profiles and to delay the separation of boundary layer, while the injection parameter decreases the velocity profiles. On the other hand, the range of solutions for the injection case is largest for $\mathrm{Al}_{2} \mathrm{O}_{3}$ nanoparticles and smallest for $\mathrm{Cu}$ nanoparticles.

\section{ACKNOWLEDGEMENT}

The researchers gratefully acknowledge the financial support received in the form of a RUGS research grant from Universiti Putra Malaysia.

\section{REFERENCES}

Abu-Nada, E., 2008. Application of nanofluids for heat transfer enhancement of separated flows encountered in a backward facing step. Int. J. Heat Fluid Flow, 29: 242-249. DOI: 10.1016/j.ijheatfluidflow.2007.07.001 
Ahmad, S. and I. Pop, 2010. Mixed convection boundary layer flow from a vertical flat plate embedded in a porous medium filled with nanofluids. Int. Commun. Heat Mass Transfer, 37: 987-991. DOI: 10.1016/j.icheatmasstransfer.2010.06.004

Arifin, N.M., F. Ismail, R. Nazar and I. Pop, 2012b. Marangoni-driven Boundary layer Flow in a nanofluid with Suction and Injection. World App. Sci. J. 17, 21-26.

Arifin, N.M., R. Nazar and I. Pop, 2012a. Free- and Mixed-Convection Flow Past a Horizontal Surface in a Nanofluid. J. Thermophys. Heat Transfer, 26: 375-382.

Arifin, N.M., R. Nazar, I. Pop, 2011. Non-isobaric marangoni boundary layer flow for $\mathrm{Cu}, \mathrm{Al}_{2} \mathrm{O}_{3}$ and $\mathrm{TiO}_{2}$ nanoparticles in a water based fluid. Meccanica, 46: 833-843. DOI: 10.1007/s11012-0109344-6

Bachok, N., A. Ishak and I. Pop, 2010. Boundary-layer flow of nanofluids over a moving surface in a flowing fluid. Int. J. Thermal Sci., 49: 1663-1668. DOI: $10.1016 /$ j.ijthermalsci.2010.01.026

Buongiorno, J., 2006. Convective transport in nanofluids. J. Heat Transfer, 128: 240-250. DOI: 10.1115/1.2150834

Cheng, P. and W.J. Minkowycz, 1997. Free convection about a vertical flat plate embedded in a porous medium with application to heat transfer from a dike. J. Geophy. Res., 82: 2040-2044. DOI: 10.1029/JB082i014p02040

Choi, J. and L.A. Guarino, 1995. Expression of the IE1 transactivator of Autographa californica nuclear polyhedrosis virus during viral infection. Virology, 209: 99-107. PMID: 7747489

Ghasemi, B. and S.M. Aminossadati, 2010. Mixed convection in a lid-driven triangular enclosure filled with nanofluids. Int. Comm. Heat Mass Transfer, 37:

1142-1148.DOI: 10.1016/j.icheatmasstransfer.2010.06.020

Harris, S.D., D.B. Ingham and I. Pop, 2009. Mixed convection boundary-layer flow near the stagnation point on a vertical surface in a porous medium: Brinkman model with slip. Transp. Porous Media, 77: 267-285. DOI: 10.1007/s11242-008-9309-6

Imran, S.M., S. Asghar and M. Mushtaq, 2012. Mixed convection flow over an unsteady stretching surface in a porous medium with heat source. Math Prob. Eng., 2012: 485418-485432. DOI: $10.1155 / 2012 / 485418$
Ingham, D.B. and I. Pop, 2005. Transport Phenomena in Porous Media III. 1st Edn., Elsevier, Oxford, ISBN10: 0080543189, pp: 450.

Jou, R.Y. and S.C. Tzeng, 2006. Numerical research of nature convective heat transfer enhancement filled with nanofluids in rectangular enclosures. Int. Commun. Heat Mass Transfer, 33: 727-736. DOI: 10.1016/j.icheatmasstransfer.2006.02.016

Khan, W.A. and I. Pop, 2010. Boundary-layer flow of a nanofluid past a stretching sheet. Int. J. Heat Mass Transfer, 53: 2477-2483. DOI: 10.1016/j.ijheatmasstransfer.2010.01.032

Khanafer, K., K. Vafai and K. Vafai, 2003. Buoyancydriven heat transfer enhancement in a twodimensional enclosure utilizing nanofluids. Int. J. Heat Mass Transfer, 46: 3639-3653.

Kuznetsov, A.V. and D.A. Nield, 2010. Natural convective boundary-layer flow of a nanofluid past a vertical plate. Int. J. Thermal Sci., 49: 243-247. DOI: 10.1016/j.ijthermalsci.2009.07.015

Meade, D.B., B.S. Haran and R.E. White, 1996. The shooting technique for the solution of two-point boundary value problems. Maple Tech., 3: 85-93.

Mukhopadhyay, S., 2012. Mixed convection boundary layer flow along a stretching cylinder in porous medium. J. Pet. Sci. Eng., 96-97: 73-78. DOI: 10.1016/j.petrol.2012.08.006

Muthtamilselvan, M., P. Kandaswamy and J. Lee, 2010. Heat transfer enhancement of copper-water nanofluids in a lid-driven enclosure. Comm. Nonlinear. Sci. Numer. Simulat, 15: 1501-1510. DOI: 10.1016/j.cnsns.2009.06.015

Nield, D.A. and A. Bejan, 2006. Convection in Porous Media. 3rd Edn., Springer, New York, ISBN-10: 0387290966, pp: 640.

Nield, D.A. and A.V. Kuznetsov, 2009. The ChengMinkowycz problem for natural convective boundary-layer flow in a porous medium saturated by a nanofluid. Int. J. Heat Mass Transfer, 52: 57925795 .

DOI: 10.1016/j.ijheatmasstransfer.2009.07.024

Oztop, H.F. and E. Abu-Nada, 2008. Numerical study of natural convection in partially heated rectangular enclosures filled with nanofluids. Int. J. Heat Mass Transfer, 29: 1326-1336. DOI: 10.1016/j.ijheatfluidflow.2008.04.009

Pop, I. and D.B. Ingham, 2001. Convec eat transfer augmentation in a two-sided lid-driven differentially heat square cavity utilizing nanofluids. Int. J. Heat Mass Transfer, 50: 2002-2018. 
Rosali, H., A. Ishak and I. Pop, 2011. Mixed convection stagnation-point flow over a vertical plate with prescribed heat flux embedded in a porous medium: Brinkman-extended darcy formulation. Transp. Porous Med., 90: 709-719. DOI 10.1007/s11242011-9809-7

Tiwari, R.K. and M.K. Das, 2007. Heat transfer augmentation in a two-sided lid-driven differentially heated square cavity utilizing nanofluids. Int. J. Heat Mass Transfer, 50: 2002-2018. DOI: 10.1016/j.ijheatmasstransfer.2006.09.034
Vadasz, P., 2008. Emerging Topics in Heat and Mass Transfer in Porous Media. 1st Edn., Springer, New York, ISBN-10: 1402081782, pp: 328.

Yasin, M. H. M., N.M. Arifin, R. Nazar, F. Ismail and I. Pop, 2012. Mixed convection boundary layer with internal heat generation in a porous medium filled with a nanofluid. Adv. Sci. Lett., 13: 833-835. DOI: 10.1166/asl.2012.3863 